\title{
Papers
}

\section{Randomised controlled trials in Africa of HIV and AIDS: descriptive study and spatial distribution}

\author{
Nandi Siegfried, Mike Clarke, Jimmy Volmink
}

\begin{abstract}
Objectives To identify and describe randomised controlled trials on HIV and AIDS conducted in Africa and to map their spatial distribution using exact geographic coordinates. Design Construction and analysis of a database of trials conducted wholly or partly in Africa and reported before 2004. Data sources CENTRAL, Medline, Embase, and LILACS. Results Our comprehensive search yielded 284 distinct records that were potentially eligible for inclusion in the database. Of these, 150 articles reported on 77 eligible trials published or reported from 1987 to 2003. Seven trials were identified exclusively from the CENTRAL database. Trials were conducted in 18 of 48 countries in sub-Saharan Africa. None were conducted in north Africa. Only 19 had a principal investigator located in an African country. Forty two trials assessed prevention and 35 assessed treatment. Most studies were funded by government agencies outside Africa $(n=43)$, with the pharmaceutical industry providing partial support to 16 of these. The pharmaceutical industry provided full or partial support to a further 18 trials. Only 43 trials reported conducting a power calculation for determining sample size. There was no mention of ethical approval or informed consent in 19 and 17 trials, respectively.

Conclusion The relatively small number of HIV/AIDS trials conducted in Africa is not commensurate with the burden of disease. Geographical mapping as an adjunct to prospective trial registration is a useful tool for researchers and decision makers to track existing and future trials.
\end{abstract}

\section{Introduction}

The randomised controlled trial is the best study design to determine whether an intervention is effective. ${ }^{1}$ Wherever possible, decisions to use particular interventions should be based on evidence from well conducted randomised trials. Over two million Africans died from AIDS in 2003, and women and children are disproportionately represented in this figure. ${ }^{2}$ People with HIV and AIDS, clinicians, policy makers, health activists, and many other key players require information on the most effective forms of prevention and treatment relevant to their setting. Researchers and funders of research also require knowledge of current trials to better address gaps and disparities in research. ${ }^{3}{ }^{4}$

We have assembled a database of African-based trials of prevention and treatment interventions for HIV and AIDS as part of a larger study to compare the methods of these trials with those conducted elsewhere. We have described all African trials reported before the end of 2003.

\section{Methods}

We identified all records pertaining to HIV or AIDS in PubMed (see bmj.com) and added a sensitive filter to identify all possible reports of relevant randomised trials. ${ }^{5}$ We searched the Central Register of Controlled Trials (CENTRAL) (issue 2, 2004); the National Library of Medicine Medline database (via PubMed on 16 August 2004); Embase via OVID (on 4 September 2004); and Latin American and Caribbean Health Sciences Literature (LILACS) (on 4 December 2004).

Searching these databases in the second half of 2004 allowed us to capture all reports up to 2003 by avoiding the delay between reporting and indexing in the database. The search was not limited by language. We included LILACS to increase our yield of trials from Portuguese speaking Africa and Embase to improve coverage of journals in European languages other than English.

One of us (NS) read each abstract to determine eligibility (table 1). Two experienced hand searchers screened all the retrieved abstracts for controlled trials, regardless of location. One of us (MC) checked the sample they identified for any African randomised controlled trials as a quality control measure. We obtained full articles of all potentially eligible trials and those about which we were uncertain. NS read these articles, determined final eligibility, and extracted data using a standardised form developed specifically for this project (table 2). The data were entered on a specifically designed MSAccess database.

Analysis

Data are presented as numbers and simple frequencies calculated in MS Excel. Descriptive statistics and qualitative information are presented when appropriate.

\section{Mapping}

For trial location, we recorded the geographic coordinates of each trial and used geographic mapping software (MapInfo) to plot the position of each trial.

\section{Results}

\section{Search results}

We retrieved 440 records from CENTRAL, 47 from LILACS, 7734 from PubMed, and 4594 from Embase. We identified 284 discrete potentially eligible records from all the searches and obtained the full articles. The reliability of rating between NS and MC was $>91 \%$. After reading each article, NS identified 150

The search terms and the full list of references for included trials can be found on bmj.com 
Table 1 Eligibility criteria for randomised controlled trials included in database

\begin{tabular}{lll} 
& \multicolumn{1}{c}{ Inclusion criteria } & \multicolumn{1}{c}{ Exclusion criteria } \\
\hline Intervention & $\begin{array}{l}\text { Efficacy or effectiveness of } \\
\text { HIV/AIDS specific intervention, } \\
\text { including pilot studies }\end{array}$ & Safety and acceptability trials \\
& $\begin{array}{l}\text { Efficacy or effectiveness of } \\
\text { non-HIV/AIDS specific } \\
\text { intervention, but with subgroup } \\
\text { of at least 5\% ( } \mathrm{n}>10 \text { ) HIV } \\
\text { positive participants }\end{array}$ & $\begin{array}{l}\text { Trials assessing behavioural } \\
\text { interventions without measuring HIV } \\
\text { incidence }\end{array}$ \\
& $\begin{array}{ll}\text { Conducted wholly in Africa, or } \\
\text { partly if multinational trial }\end{array}$ & $\begin{array}{l}\text { Trials conducted on Africans living } \\
\text { outside continent }\end{array}$ \\
\hline Location & $\begin{array}{l}\text { Infected with HIV-1, HIV-2 or } \\
\text { dually infected, or in case of } \\
\text { Prevention trials, HIV negative, }\end{array}$ & \\
& but at risk of HIV & \\
\hline Trial date & $\begin{array}{l}\text { Reported before 2004 (if } \\
\text { preliminary data only, authors } \\
\end{array}$ & \\
\hline
\end{tabular}

Table 2 Data extraction items for each trial

\begin{tabular}{ll}
\begin{tabular}{ll} 
Item \\
\hline Reference
\end{tabular} & \multicolumn{1}{c}{ Details recorded } \\
\hline Intervention & Preventication citation; source database(s) \\
\hline Location & $\begin{array}{l}\text { Single or multicentre; city; region; country; geographic } \\
\text { coordinates; details of other countries if multinational trial }\end{array}$ \\
\hline Principal investigator & Name; affiliation; qualifications; country of residency \\
\hline Funder & $\begin{array}{l}\text { African; non-African; government agency; non-government agency; } \\
\text { inter-government agency; pharmaceutical }\end{array}$ \\
\hline Ethical approval & $\begin{array}{l}\text { African committee; non-African committee; method of informed } \\
\text { consent }\end{array}$ \\
\hline Methods & Sample size; power calculation \\
\hline
\end{tabular}

articles dealing with a total of 77 randomised controlled trials (figure 1) (see bmj.com for full list of trials and articles).

\section{Article details}

Sixty eight of the 77 trials were reported in articles retrieved by the PubMed search, either exclusively (three) or in combination with the CENTRAL and Embase searches. We retrieved seven trials exclusively from CENTRAL and two exclusively from Embase. No eligible articles were retrieved from LILACS.

We identified 71 of the 77 trials from full journal articles. Three of the trials were reported only in conference proceedings, and three were identified from news articles retrieved in the searches with additional information being obtained directly from the original authors (three of these trials are unpublished). A large proportion of the 150 articles were published in the journals Lancet $(\mathrm{n}=28)$ and AIDS $(\mathrm{n}=28)$. Twelve articles appeared in the Journal of Acquired Immune Deficiency Syndrome, and five articles each in the Journal of Infectious Diseases, Clinical Infectious Diseases, and the New England Journal of Medicine. The rest were published in 50 other journals and indexed news bulletins. Four of these were from the French journals of Santé, Revue des Maladies Respiratoires, Annales de la Société Belge de Médecine Tropicale, and Pathologie et Biologie. Thirty trials had been published in more than one article, with one trial of micronutrient supplementation to prevent mother-to-child transmission being published in nine different articles. ${ }^{6}$

\section{Principal investigators}

Not every trial clearly reported the identity of the principal investigator. When we were uncertain, we classified the first author of the main trial report as the principal investigator. The principal investigator was based in the United States for 23 trials and in the United Kingdom for eight trials. Other principal investigators based outside Africa were from Australia (1), Belgium (3), Canada (3), Denmark (1), France (4), Ireland (3), Germany (2), Sweden (1), Switzerland (1), and the Netherlands (4). The principal investigators based within Africa were from Côte d'Ivoire (4), Kenya (2), Malawi (2), South Africa (4), Zambia (3), and Zimbabwe (4). We could not identify the location of the principal investigator for two trials.

\section{Trial characteristics}

Forty two trials assessed prevention interventions and 35 were treatment trials.

For prevention, we categorised interventions to reduce transmission from mother to child (13); drugs for preventing opportunistic infections (12); microbicides (5); behavioural interventions (5); drugs for preventing HIV transmission (such as treatment of sexually transmitted infection) (4); and other prevention measures (such as nutritional supplements) (3). We did not find any completed trials of vaccine efficacy.

Treatment trials included drug treatment of HIV and AIDS (7); drug treatment of opportunistic infections (12); drug treatment of other infections in people with HIV and AIDS (11); and other treatments (such as nutritional supplementation) (5). None of the trials assessed behavioural treatments for HIV and AIDS.

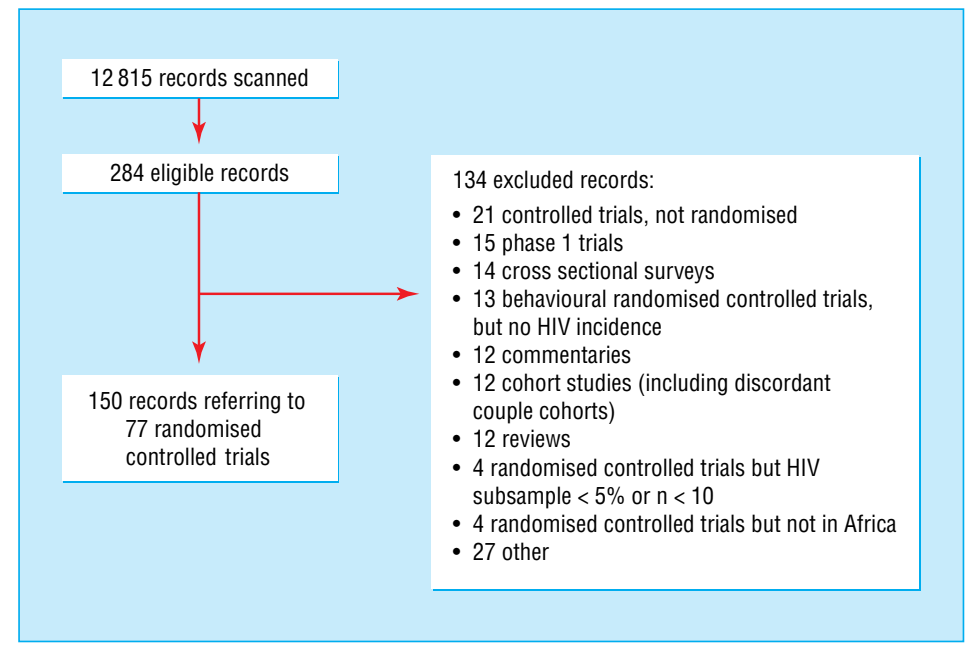

Fig 1 Inclusion of trials in database 


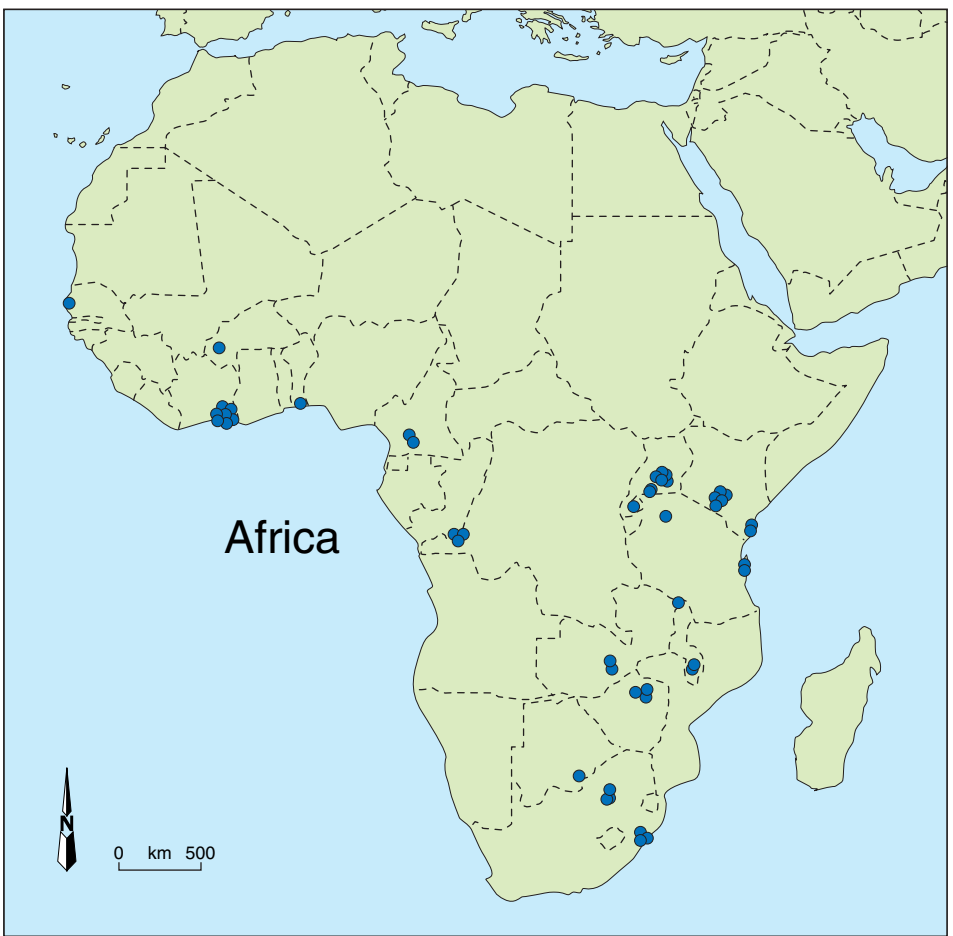

Fig 2 Randomised controlled trials of prevention of HIV and AIDS, 1987-2003. Circles indicate site of trial based on geographic coordinates. N=42 (some trials have more than one country location)

The earliest trial started in 1987 and assessed the preventive efficacy of a microbicide, nonoxinol 9 gel, among 138 women in Nairobi, Kenya. ${ }^{7}$ Two other studies, both conducted in what was then Zaire (now the Democratic Republic of Congo), began before $1990 .{ }^{8}$ Start dates were uncertain for 15 trials, and the 59 remaining trials began during the 1990 s or early 2000 s.

\section{Location and mapping}

Figures 2 and 3 show the location of the trials categorised according to prevention or treatment. Trials have been conducted in 18 of the 48 countries of sub-Saharan Africa with no trials in north Africa. Forty two trials were single centre studies and 25 were multicentre trials done within a single African

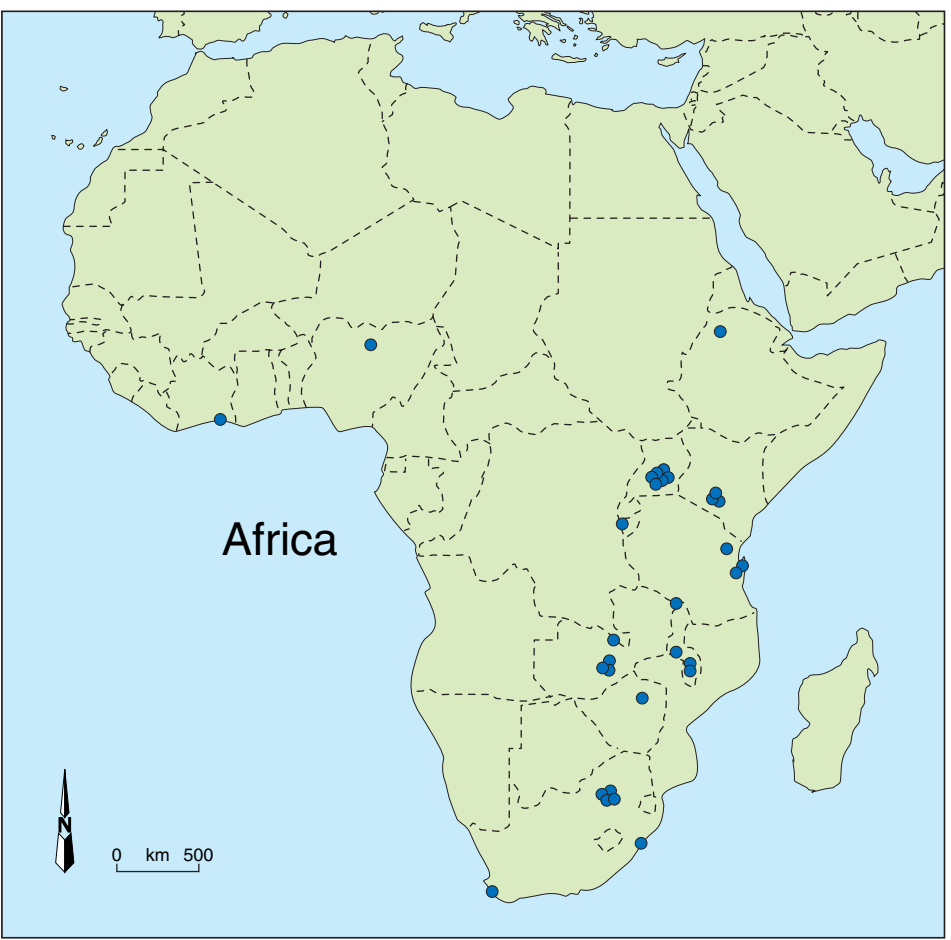

Fig 3 Randomised controlled trials of treatment of HIV and AIDS, 1987-2003. Circles indicate site of trial based on geographic coordinates. N=33 (coordinates were not available for two trials) 
country. Nine trials were multinational multicentre trials, five of which took place in more than one African country. The four other trials were conducted across continents.

\section{Sample size and quality of methods}

Sample size ranged from 16 participants in a nutritional supplement trial conducted in a rural area of Uganda $^{10}$ to 39836 participants in a trial assessing a pneumococcal conjugate vaccine in HIV positive and HIV negative children in Soweto, South Africa. ${ }^{11}$ In 43 trials authors reported conducting an a priori power calculation, but this was unclear or not reported in the other trials.

Sixty eight trials compared two interventions or strategies, five included three comparison groups, two included four, one included five, and one had six. All, apart from one crossover trial, used a parallel randomised design. Simple randomisation was reported in 33 trials and simple stratified randomisation in one trial. Forty three reported using blocked or blocked stratified randomisation. Most trials (73) were randomised at the individual level. Four were cluster trials, three of which were large prevention trials (with more than 12000 participants) assessing the effectiveness of both pharmaceutical and behavioural treatment for sexually transmitted infections on preventing HIV transmission. ${ }^{12-14}$ Cluster correlation coefficients were used in the analyses of all three trials. A smaller prevention trial of peer education in 2219 factory workers in Zimbabwe was also cluster randomised but did not report using a cluster correlation coefficient in its analysis. ${ }^{15}$ Thirteen trials reporting on mother to child transmission were all randomised at the individual level.

\section{Funding and ethics}

We could not identify the primary funder for every trial-for example, when trials were funded by more than one source. Government agencies outside of Africa provided funding to 43 trials (table 3 ). The pharmaceutical industry provided full or partial funding, or provided drugs and placebo treatments, to 34 trials. Sixteen of the trials that were funded by governments outside Africa also received funding from the pharmaceutical industry. Twenty three trials received funding from international non-government and inter-government agencies such as the World Health Organization and UNAIDS. African government agencies and African non-government agencies provided funding to five trials. Funding was not reported for four treatment trials and one prevention trial.

Fifty eight trials reported receiving ethical approval from an approving authority, with 39 trials receiving approval from both local African and non-African institutions. Nineteen trials did not report on ethical approval; of which 13 were treatment trials and 10 were trials of drugs. Informed consent was obtained in writing in 34 trials, orally in 7 trials, and by unspecified methods in 19 trials. Consent was not reported in the 17 other trials.

\section{Discussion}

This is the first comprehensive attempt to identify and describe all randomised controlled trials on HIV and AIDS conducted in Africa up to 2003. It is innovative in displaying the extent and scope of the trials graphically by linking the data directly to geographic coordinates. This provides an immediate and accessible overview of the current status of trial evidence.

\section{Strengths and weaknesses}

A major strength of our study is the extremely broad search and the lack of language restrictions. We contacted authors for additional information for the small number of trials that were
Table 3 Details of non-African government agencies providing trial funding

\begin{tabular}{|c|c|}
\hline Country and government agency & $\begin{array}{c}\text { No of trials } \\
\text { funded/agency* }\end{array}$ \\
\hline \multicolumn{2}{|l|}{ Australia: } \\
\hline AUSAid & 1 \\
\hline Australian National Council of AIDS & 1 \\
\hline National Centre in HIV Epidemiology and Clinical Research & 1 \\
\hline \multicolumn{2}{|l|}{ Austria: } \\
\hline International Atomic Energy Agency & 1 \\
\hline \multicolumn{2}{|l|}{ Belgium: } \\
\hline Belgian Administration for Development and Cooperation & 2 \\
\hline National Fonds voor Wetenschappelijk Onderzoek & 1 \\
\hline \multicolumn{2}{|l|}{ Canada: } \\
\hline Medical Research Council & 3 \\
\hline Ontario HIV Treatment Network & 1 \\
\hline Canadian Infectious Diseases & 1 \\
\hline \multicolumn{2}{|l|}{ Denmark: } \\
\hline Danish International Development Assistance & 1 \\
\hline \multicolumn{2}{|l|}{ France: } \\
\hline French agency of research on AIDS (ANRS) & 4 \\
\hline Ministry of Cooperation & 3 \\
\hline \multicolumn{2}{|l|}{ Germany: } \\
\hline Centre for International Migration and Development & 1 \\
\hline \multicolumn{2}{|l|}{ Japan: } \\
\hline Ministry of Education, Science and Culture & 1 \\
\hline \multicolumn{2}{|l|}{ Netherlands: } \\
\hline Royal Netherlands Embassy of Zambia & 1 \\
\hline Dutch Ministry of Welfare, Health and Sport & 1 \\
\hline \multicolumn{2}{|l|}{ Sweden: } \\
\hline Swedish International Development Cooperation Agency & 1 \\
\hline Swedish Heart and Lung Foundation & 1 \\
\hline Swedish Research Council & 1 \\
\hline \multicolumn{2}{|l|}{ United Kingdom: } \\
\hline British Council & 1 \\
\hline Medical Research Council & 4 \\
\hline Overseas Development Fund & 2 \\
\hline Department of International Development & 3 \\
\hline \multicolumn{2}{|l|}{ United States: } \\
\hline \multicolumn{2}{|l|}{ National Institutes of Health $(\mathrm{NIH})$ : } \\
\hline Fogarty International Center & 7 \\
\hline HIV Network for Prevention Trials & 1 \\
\hline National Institute of Allergy and Infectious Diseases & 3 \\
\hline National Institute of Child Health and Human Development & 3 \\
\hline World AIDS Foundation & 1 \\
\hline NIH grant to Family Health International & 1 \\
\hline \multicolumn{2}{|l|}{ Veterans' Affairs Research Service } \\
\hline Center for Diseases Control and Prevention, Atlanta & 4 \\
\hline US Agency for International Development & 5 \\
\hline Armed Forces Institute of Pathology & 1 \\
\hline \multicolumn{2}{|l|}{ Europe: } \\
\hline European Commission & 3 \\
\hline
\end{tabular}

*Numbers are not exclusive as some agencies cofund the same trial.

described only in news articles and expect that contacting the authors of every trial would yield additional information. ${ }^{16} \mathrm{~A}$ thorough search of conference proceedings might also be useful. Although recent research has shown that conference abstracts might not accurately summarise subsequent full reports, ${ }^{17}$ the fact that about half the research reported at conferences does not get published in full might make such abstracts a useful source of additional trials. ${ }^{18}$

\section{The 10/90 disequilibrium}

A remarkable finding from our study is how few HIV/AIDS trials have been conducted on the African continent over the past two decades. It highlights the gulf between the global burden of disease and research on intervention, the so called 10/90 
disequilibrium, ${ }^{19-21}$ and confirms previous findings that HIV/ AIDS trials are under-represented in sub-Saharan research. ${ }^{22}$ Most of the trials were funded by government agencies outside Africa, followed by pharmaceutical companies and international non-government and inter-government organisations. This may reflect a lack of economic ability, political will, or research capacity to conduct intervention research in African countries. Commercial funding is a source of potential bias in trials and may influence results. ${ }^{2324}$ Although we are not aware of any evidence to link non-commercial agency sponsorship to biased results, research funded by such organisations may be driven by priorities different from those of the country where the trial is done. ${ }^{25} 26$

Few principal investigators were based in African countries, although it is possible that a proportion of principal investigators were of African origin and working abroad. ${ }^{27}$ Despite this uncertainty, it suggests that publication of trial results continues to be driven by researchers external to the continent. It is difficult to predict how this impacts on African collaborating researchers, but it does suggest that transfer of skills and knowledge to local researchers must remain a fundamental aim of any trial conducted in Africa. ${ }^{25}$

\section{Ethical issues}

Nineteen of the 77 trials did not report on whether ethical approval had been obtained. Although this may simply reflect inadequate reporting, it is also possible that ethical approval may not have been obtained. In a survey of 203 researchers living in developing countries, Hyder and colleagues found that $44 \%$ of respondents reported that their studies did not undergo any review (technical, scientific, or ethical) in the country where the study was done. ${ }^{28}$ They argued that ethical review in both the host and the donor country should be standard in collaborative research. Only half of the HIV/AIDS trials in Africa met this standard.

\section{Conclusions}

A major challenge for a database such as that created in this study is keeping up to date so as to provide useful information for patients, carers, clinicians, researchers, and policy makers. To facilitate this, we endorse prospective trial registration, which will make key trial information accessible to the public at no charge. ${ }^{29}{ }^{30}$ In addition, we recommend that those responsible for trial registers should consider including geographic coordinates for the trial to allow graphical display of geographic data.

We are grateful to the authors who provided us with additional information on their trials. We thank Anne Eisinga for her assistance with the development and conduct of the searches, Sarah Moore and Tara Horvath for article retrieval, Karishma Busgeeth for French translations, and George Rutherford for Portuguese translations. We are indebted to Nigel James of the Oxford Bodleian mapping room for assistance with the geographic information system software.

Contributors: NS had the original idea to compare trial quality of HIV/AIDS trials in different locations. NS developed the study design under the supervision of MC and JV, conducted the data collection and analysis, wrote the first draft of the paper, and is guarantor. MC monitored and checked data collection. All authors contributed to the interpretation of results and edited the manuscript for important scientific content.

Funding: Nandi Siegfried is sponsored by the Nuffield Dominions Trust.

Competing interests: None declared.

Ethical approval: Not required.

1 Schulz KF, Grimes DA. Generation of allocation sequences in randomised trials: chance, not choice. Lancet 2002;359:515-9.

2 UNAIDS. 2004 report on the global AIDS epidemic. Geneva: Joint United Nations Programme on HIV/AIDS, 2004 .

3 Programme on HIV/AIDS, 2004. tries. Health Res Policy Syst 2004;2:6.

\section{What is already known on this topic}

People living in sub-Saharan Africa carry the heaviest burden of HIV and AIDS, with an estimated 25 million individuals infected with HIV

Randomised trials and systematic reviews of these provide the most reliable way to assess the relative effects of different interventions for both prevention and treatment

\section{What this study adds}

In the past 20 years, of the many randomised controlled trials on HIV and AIDS only 77 (42 prevention, 35 treatment) have been conducted on the African continent and few principal investigators were based in African countries

Most of the 77 trials were funded by government agencies or non-governmental organisations outside Africa and by pharmaceutical companies

Mapping trials with geographic coordinates is a useful tool for researchers and decision makers to keep track of existing and future trials

4 Fraser D. Overlooked opportunities for investing in health research and development Bull World Health Organ 2000;78:1054-61.

5 Dickersin K, Scherer R, Lefebvre C. Identifying relevant studies for systematic reviews. BMJ 1994;309:1286-91

6 Fawzi WW, Msamanga G, Hunter D, Urassa E, Renjifo B, Mwakagile D, et al. Randomized trial of vitamin supplements in relation to vertical transmission of HIV-1 in Tanzania.J Acquir Immune Defic Syndr 2000;23:246-54.

7 Kreiss J, Ngugi E, Holmes K, Ndinya-Achola J, Waiyaki P, Roberts PL, et al. Efficacy of nonoxynol 9 contraceptive sponge use in preventing heterosexual acquisition of HIV in Nairobi prostitutes. JAMA 1992;268:477-82.

8 Nyst MJ, Perriens JH, Kimputu L, Lumbila M, Nelson AM, Piot P. Gentian violet, ketoconazole and nystatin in oropharyngeal and esophageal candidiasis in Zairian AIDS conazole and nystatin in oropharyngeal and esop
patients. Ann Soc Belg Med Trop 1992;72:45-52.

9 Perriens JH, St Louis ME, Mukadi YB, Brown C, Prignot J, Pouthier F, et al. Pulmonary tuberculosis in HIV-infected patients in Zaire. A controlled trial of treatment for either 6 or 12 months. N Engl J Med 1995;332:779-84.

10 Byrne D, Mathias P, Mulvaney M, Male-Kawuma M. The effect of nutritional supplementation on weight and clinical management of patients with human immunodeficiency virus (HIV) infection in rural Uganda. Proc Nutr Soc 1999;58:154A.

11 Klugman KP, Madhi SA, Huebner RE, Kohberger R, Mbelle N, Pierce N. A trial of a 9-valent pneumococcal conjugate vaccine in children with and those without HIV infection. N Engl J Med 2003;349:1341-8.

12 Grosskurth H, Mosha F, Todd J, Mwijarubi E, Klokke A, Senkoro K, et al. Impact of improved treatment of sexually transmitted diseases on HIV infection in rural Tanzania: randomised controlled trial. Lancet 1995;346:530-6.

13 Wawer MJ, Sewankambo NK, Serwadda D, Ouinn TC, Paxton LA, Kiwanuka N, et al. Control of sexually transmitted diseases for AIDS prevention in Uganda: a randomised Control of sexually transmitted diseases for AIDS prevention in Ugan
community trial. Rakai Project Study Group. Lancet 1999;353:525-35.

14 Kamali A, Quigley M, Nakiyingi J, Kinsman J, Kengeya-Kayondo J, Gopal R, et al. Syndromic management of sexually-transmitted infections and behaviour change interventions on transmission of HIV-1 in rural Uganda: a community randomised trial. Lancet 2003;361:645-52.

15 Bassett M. Impact of peer education on HIV infection in Zimbabwe. Sex Health Exch 1998;4:14-5.

16 Devereaux PJ, Choi PT, El-Dika S, Bhandari M, Montori VM, Schünemann HJ, et al. An observational study found that authors of randomized controlled trials frequently use concealment of randomization and blinding, despite the failure to report these methods. J Clin Epidemiol 2004;57:1232-6.

17 Hopewell S. Trials reported as abstracts and full publications: how do they compare? [abstract]. Clinical Trials 2004;1(suppl 1):216-7.

18 Scherer R, Langenberg P, von Elm E. Full publication of research results initially presented in abstracts. Cochrane Database of Methodology Rev 2005;(2):CD000005.

19 World Health Organization. Investing in health research and development: report of the ad hoc committee on health research relating to future intervention options. Geneva: WHO, 1996.

20 Nuffield Council on Bioethics. The ethics of research related to healthcare in developing countries. London: Nuffield Council on Bioethics, 2002.

21 Yusuf S. Clinical research and trials in developing countries. Stat Med 2002;21:2859-67.

22 Isaakidis P, Swingler GH, Pienaar E, Volmink J, Ioannidis JPA. Relation between burden of disease and randomised evidence in sub-Saharan Africa: survey of research. BMJ 2002;324:702-5.

23 Lexchin J, Bero LA, Djulbegovic B, Clark O. Pharmaceutical industry sponsorship and research outcome and quality: systematic review. BMJ 2003;326:1167-70.

24 Bhandari M, Busse JW, Jackowski D, Montori VM, Schunemann H, Sprague S, et al. Association between industry funding and statistically significant pro-industry findings in medical and surgical randomized trials. CMAJ 2004;170:477-80. 
25 Edejer T. North-South research partnerships: the ethics of carrying out research in developing countries. BMJ 1999;319:438-41.

26 Anonymous. Brazil leads from the front on AIDS. Lancet 2005;365:1664.

27 Bhandari M, Busse JW, Kulkarni AV, Devereaux PJ, Leece P, Guyatt GH. Interpreting authorship order and corresponding authorship. Epidemiology 2004;15:125-6.

28 Hyder AA, Wali SA, Khan AN, Teoh NB, Kass NE, Dawson L. Ethical review of health research: a perspective from developing country researchers. J Med Ethics 2004;30:6872.

29 De Angelis C, Drazen JM, Frizelle FA, Haug C, Hoey J, Horton R, et al. Clinical trial registration: a statement from the international committee of medical journal editors. Lancet 2004:364:911-2.

30 Krleza-Jeric K, Chan A, Dickersin K, Sim I, Grimshaw J, Gluud C. Principles for international registration of protocol information and results from human trials of health related interventions: Ottawa statement (part 1). BMJ 2005;330:956-8.
(Accepted 31 August 2005)

bmj.com 2005;331:742

UK Cochrane Centre, Oxford OX2 7LG

Nandi Siegfried South African Nuffield medical fellow

Mike Clarke director

Primary Health Care Directorate, University of Cape Town, Cape Town, South Africa

Jimmy Volmink professor

Correspondence to: N Siegfried nsiegfried@cochrane.co.uk 